y el espejo de la fontana

al zambullirse de la rana

¡hace chás!

Si los comparamos con dos versiones del kai-ku de Matsúo Basho (16441694),
El estanque antiguo.
El viejo estanque:
Salta una rana.
salta una rana,
El ruido del agua ${ }^{4}$.
el sonido del agua ${ }^{5}$,

observamos que, dejando a un lado los rasgos esperpénticos (espejo, al zambullirse, hace chás) con que Valle degrada grotescamente la descripción, los elementos son semejantes y se presentan en el mismo orden. Podría objetarse que la secuencia es lógica y que pudo ocurrírsele independientemente a cada autor. Pero ante el estrecho parecido entre el hai-ku y los tres últimos versos de la apostilla - tres también como en el poemita-, cabe preguntarse hasta qué punto Valle conoció la poesía japonesa y cómo llegó a ella ${ }^{6}$. Además, ¿el calco intencionadamente deformante de Valle-Inclán no será otra de sus críticas al modernismo, dirigida esta vez contra el gusto por las japonerías? ¿O será únicamente un ataque sarcástico contra las inclinaciones literarias de ciertos grupo más recientes??

El Colegio de México.

Emma Susana Speratit Piñero

\title{
LOS SUPUESTOS "PRECURSORES" DEL MODERNISMO HISPANOAMERICANO
}

Sorprende que todavía hoy se califique de "precursores" del modernismo a José Asunción Silva, Julián del Casal, Manuel Gutiérrez Nájera y José Martí', escritores modernistas ciento por ciento, y algunos de los cuales se equiparan en grandeza creadora al supuesto fundador único de ese movimiento, Rubén Darío. Cometió un evidente error crono-

observarse en Tablado de marionetas (Opera omnia, vol. 10, 1930, p. 252), donde se reproduce la obra, aunque allí se lee zambullido en lugar de zambullirse.

- Donald Keene, La literatura japonesa, Fondo de Cultura Económica, México, 1956, p. 55 (Breviarios, núm. 112).

"Octavio Paz, "La poesia de Matsúo Basho", prólogo a Las sendas de Oku, Imprenta Universitaria, México, 1957, p. 18.

- Si la composición de Basho aparece en A. Poncin y Julien Vocance, Epigrammes lyriques du Japon (1910), alli pudo haberla leído Valle.

"Carlos García Prada, "La poesía imaginista y el hai-kai japonés", Revib, núms. $4^{1-4^{2}}$, p. $3^{83}$, sostiene que el "Bestiario" de Valle es un "sartalito" de hai-kais. Sorprende que se le haya escapado el hai-ku propiamente dicho.

${ }^{\prime}$ El último que los ha clasificado como tales es Bernard Gicovate, Julio Herrera y Reissig and the Symbolists, libro que reseñamos en este mismo número de la NRFH, pp. 85-88. El libro de Gicovate se publicó en 1957 , pero ya tres años antes MAx Henríouez Ureña había expuesto lúcidamente la verdad de los hechos en su Breve historia del modernismo, México, 1954. 
lógico el primero que "calificó de "precursoras" formas poéticas que se escribieron años después de la fecha en que generalmente se fija la génesis del modernismo"'. Por lo demás, no se inició este movimiento con la publicación de $A z u l . .$. , según suele afirmarse: sus albores se remontan al lustro $1875^{-1880}$, cuando Martí y Gutiérrez Nájera ensayan formas estilísticas pertenecientes a una estética que luego se llamaría modernista.

Es probable que el propio Darío haya contribuido a la divulgación de la cronología inexacta que aquí combatimos, pues dice, por ejemplo: "E1 movimiento de libertad que me tocó iniciar en América. .." (1915)"; pero la realidad histórica y las recientes revaloraciones del modernismo no apoyan semejante afirmación.

El modernismo -como el Renacimiento o el romanticismo- es una época y no una escuela, y la unidad de esa época consistió en producir grandes poetas individuales, que cada uno se define por la unidad de su personalidad, y todos juntos por el hecho de haber iniciado una literatura independiente, de valor universal, que es principio y origen del gran desarrollo de la literatura hispanoamericana posterior. El primero y más grande de los creadores de esta época fue José Martí, que en su prosa lírica -ensayos, discursos, cartas-y en sus versos libres o sencillos inicia. con uno de los estilos más personales de la lengua castellana, los temas y actitudes que van a perdurar y desarrollarse de manera varia, y creciente hasta hoy... Contemporánea de él es la primera generación de poetas modernistas, que suelen llamarse precursores, pero que en rigor son los creadores de la nueva literatura en el verso y la prosa..."

Ciertamente tuvo precursores el modernismo, pero éstos no fueron Silva, Casal, Gutiérrez Nájera y Martí, sino una legión de prosistas y poetas como Cané, Sarmiento, Altamirano, Hostos, Varona, Pombo, Pérez Bonalde, Sierra y otros muchos que sería largo enumerar ${ }^{\overline{5}}$.

La rectificación de la cronología del modernismo ha traído consigo, lógicamente, la revaloración de la prosa rítmica y musical anterior a Dario. La trascendencia estética de esta prosa, desatendida por la crítica tradicional, comienza ya a analizarse conforme a las técnicas elaboradas por la estilística moderna, y se ha descubierto, no sólo su altísimo rango artístico, sino también su prioridad cronológica dentro del movimiento de "libertad" que Darío creía haber iniciado. A la prosa cupo el honor de inaugurar el modernismo.

La prosa modernista, rica en imágenes, variada en ritmos, plástica y sensual, siguió dos tendencias estilísticas - al igual que la expresión poética posterior- ya de 1877 a 1882 . La primera de estas tendencias caracteriza la obra del gran Martí, quien a partir de 1876 desplegó su poder de creación innovadora en una prosa "suya en sí misma"; y "este hecho de ser individual e inclasificable es el carácter esencial de la nueva época que con él más que con nadie empieza"6. En lugar de la anqui-

" M. P. González, "José Marti: jerarca dei modernismo", Miscelánea... Fernando Ortiz, La Habana, 1956, p. 729 .

" Prólogo a Cantos de vida y esperanza, Madrid, 1917, p. 9 (Obras completas, 8).

* F. DE ONís, "La poesía hispanoamericana", CCL, 1956, núm. 21, p. 17.

"Sobre esta cuestión véase M. P. González, art. cit., p. $73^{6 .}$

- F. DE ONís, "José Martí..., Valoración", RHM, 18 (1952), 148. 
losada expresión literaria que por entonces dominaba, Martí se sirvió de una prosa enraizada en el arte de las grandes figuras del Siglo de Oro, Santa Teresa, Cervantes, Quevedo, Gracián, Saavedra Fajardo, legado enriquecido con las formas estilísticas de la literatura francesa coetánea -simbolistas, impresionistas, parnasianas-, con las que Martí estaba familiarizado ya en esos años. Martí plasmó todo ello en un conjunto armónico, cromático, musical, profundamente suyo, y fue siempre consciente del cambio que estaba operando en la expresión literaria, como lo demuestra el nutrido corpus de ideas estéticas que acompaña sus innovaciones estilisticas ${ }^{7}$.

El arte de la prosa de Gutiérrez Nájera reviste modalidades distintas: mientras el cubano cultiva un estilo de entronque clásico, el mexicano prefiere una expresión eminentemente afrancesada; en aquél, las influencias francesas están asimiladas, convertidas en procedimiento y teoría propios; en éste se manifiestan de manera directa en giros y vocablos, en los ambientes parisienses, en los temas frivolos aprendidos de Catulle Mendès, Coppée, Musset, Paul de Saint-Victor y Gautier. Pero el autor de los Cuentos frágiles utiliza con tal maestría esos elementos, que en la renovación de la prosa "sólo cede el paso a José Martí. La prosa del período que podemos llamar parisiense en el modernismo y tiene su revelación más resaltante en $A z u l .$. es hija de la de Gutiérrez Nájera, aunque parezca artificiosamente trabajada"s. Esta variante afrancesada contribuyó, pues, a renovar y vigorizar el estilo literario, pero no triunfó como forma permanente; a la postre se impuso la modalidad de raigambre española, representada por Martí.

El descuido de estos hechos cronológicos suele tener como consecuencia la valoración inexacta de una obra o de un autor. A ello se debe, por ejemplo, la escasa importancia que Gicovate (op. cit., p. 7) concede a José Asunción Silva dentro de la literatura hispanoamericana; dice que Silva escribió sus mejores poemas a fines de la penúltima y durante la última década del siglo pasado ("in the late 'eighties and in the 'nineties"), "cuando Darío era ya el maestro reconocido del modernismo", y añade que este hecho les resta importancia. Conviene, sin embargo, asentar claramente la época en que aparecieron las poesías netamente renovadoras de Darío. Si los versos modernistas escritos con posterioridad a 1888 - los de Silva en este caso- no tienen mucho interés, entonces la poética modernista es muy poca cosa. Las poesías incluidas en $A z u l$... son de las menos importantes dentro de la producción rubeniana a partir de 1888. Dario era entonces un poeta en agraz que no había aplicado al verso la estilistica francesa - de Loti, de Mendés, de los Goncourt, de Gautier- incorporada en cambio en la prosa de $A z u l . .$. Limitándonos a la poesía, es innegable que Darío no adouirió categoría de creador refinado y exquisito sino cuando comenzaron a circular los poemas que luego recogió en Prosas profanas (1896), aunque los primeros atisbos de esta capacidad artística se manifestaron ya en los poemas añadidos a la segunda edición de $A z u l .$. (Guatemala, 189o).

"Sobre este aspecto véase A. A. Rogriano, "Poética y estilo de José Martf", HuT, 1 (1953), $351-378$.

s Henrfquez Ureña, op. cit., p. $7^{6}$. 
No hay en Prosas profanas una sola poesía fechada antes de 1891 , el año de la "Sinfonia en gris mayor", inspirada sin duda en el ejercicio cromático de Gautier, "Symphonie en blanc majeur". Para entonces Martí había escrito ya los tres volúmenes más importantes de su poesía, Ismaelillo, Versos libres y Versos sencillos, y la mayor parte de su estupenda prosa, a la que tanto debe la de Dario ${ }^{9}$; Gutiérrez Nájera había dado a conocer lo más destacado de su obra en verso y en prosa; Casal habia publicado Hojas al viento, y escrito casi todos los poemas de Nieve; y Silva llevaba ya varios años explorando la expresión musical en la poesía. En vista de esto, ¿cómo es posible conceder a Darío una absoluta primacía cronológica, con menosprecio de los poetas y prosistas que entre 1888 y 1891 ya habían llegado a expresiones maduras de la tendencia renovadora? Darío y los cuatro mal llamados "precursores" bebieron en análogas fuentes literarias, y algunos se dejaron influir recíprocamente. No queremos, por supuesto, rebajar los altísimos méritos poéticos del gran nicaragüense, sino sólo subrayar la precedencia cronológica y el excelso valor de los cuatro iniciadores del modernismo.

A más de las consideraciones cronológicas, en el caso de Silva hay que tener en cuenta su repudio de las exageraciones y amaneramientos en que habian caido los imitadores de Darío. Silva buscaba un camino original e individual en la expresión poética, y esta actitud explica su reiterado empleo del adjetivo peyorativo "rubendariaco", como en estos versos de la "Sinfonía color de fresa con leche":
¡Rítmica Reina lírica! Con venusinos cantos de sol y rosas de mirra y laca y polícromos cromos de tonos mil, éstos son los cáusticos versos mirrinos, ésta es la descendencia rubendariaca de la Princesa Verde y el paje Abril rubio y sutilito.

De esta parodia, de esta burla de los rubenianos, no sale indemne ni el propio Dario. Por consiguiente, resulta impropio valorar, como intenta Gicovate, la poesía de Silva a la luz de la de Dario. Cada una es grande y noble en sí, como diría el mismo Rubén.

Ivan A. Schumman

University of California at Los Angeles.

\footnotetext{
- Véase el detallado estudio de M. P. GonzÁlez, "I. Iniciación de Rubén Dario en el culto a Martí; II. Resonancias de la prosa martiana en la de Darío", Memoria del Congreso de Escritores Martianos, La Habana, 1953, pp. 503-569.

10 Poesias completas y sus mejores páginas en prosa, ed. Buenos Aires, 1944, p. 126.
} 